Journal of Applied Finance \& Banking, Vol. 12, No. 2, 2022, 27-39

ISSN: 1792-6580 (print version), 1792-6599(online)

https://doi.org/10.47260/jafb/1222

Scientific Press International Limited

\title{
The Impact of Market Factors and News Sentiments on Silver Futures ETFs
}

\author{
Yu-Min Lian', Jian-Chi Yang ${ }^{2}$ and Ko-Liang Kuo ${ }^{3}$
}

\begin{abstract}
This study constructs a multi-factor capital asset pricing model (CAPM) to analyze systematic risk and other influential risk factors in the silver futures exchangetraded funds (silver futures ETFs) market and then provides an analysis of precious metals investments as a reference. Specifically, the volatility index (VIX) and the real estate investment trusts (REITs) are used as influences of silver futures on political and economic factors. In addition, we use text mining to capture news events on the network into a Boolean matrix, which transforms unstructured data into structured data. Further, the term frequency (TF) and inverse document frequency (IDF) algorithm are applied to calculate the most important keywords on the market and measure them in the model after a sentimental evaluation. The empirical results show that the silver futures ETFs market is indeed affected by market news, providing investors in this market with a reference.
\end{abstract}

JEL classification numbers: $\mathrm{C} 10, \mathrm{C} 13, \mathrm{G} 00, \mathrm{G} 10$.

Keywords: Silver futures ETFs, Volatility index; Real estate investment trusts, Text mining, Inverse document frequency.

1 Assistant Professor, Department of Business Administration, Fu Jen Catholic University, New Taipei City, Taiwan.

2 Department of Business Administration, Fu Jen Catholic University, New Taipei City, Taiwan.

${ }^{3}$ Department of Business Administration, Fu Jen Catholic University, New Taipei City, Taiwan.

Article Info: Received: January 9, 2022. Revised: January 26, 2022.

Published online: January 31, 2022. 


\section{Introduction}

\subsection{General Background Information}

Silver has an important role in the precious metals market and is not only widely used in industrial applications but also in daily necessities and medical, solar energy, and other high-tech fields. Recently, the international political and economic situation has become unstable, and the Brexit problem has caused the gold-silver ratio to fluctuate higher than the predicted trend. Accordingly, spurred by economic uncertainty, inventors' hedge funds have increased dramatically. Especially, investors target precious-metal funds for hedge because these funds can be a form of portfolio insurance. However, investors must pay taxes when buying and selling silver, and therefore they prefer to invest in hedge funds in silver-derived goods that are exempt from taxes. Besides, the risk associated with investing in silver futures is relatively high, and such investments require professional knowledge and accurate judgment of market trends.

Accordingly, to benefit investors with more investment hedging possibilities and to provide them with a more accurate judgment of trends in the silver market, this study constructs a multi-factor capital asset pricing model (CAPM) to analyze the risk factors associated with the silver futures exchange-traded funds (silver futures ETFs) market. Incorporating the MSCI All Country World Index into the empirical research model as a systemic risk factor can provide a more accurate measure of the systemic risk of silver. The MSCI All Country World Index differs from the MSCI World Index in that constituents of the latter measure only developed countries. In contrast, constituents of the former include not only developed countries at approximately $8 \%$ but also developing and emerging countries.

In addition, the factors affecting the fluctuation of silver prices can be mainly divided into political and economic factors. They are compared with the major economic factors, such as the inflation rate, the U.S. dollar index, and changes in the supply and demand of crude oil and gold, which are recognized by general investors. The main contributions of this study are as follows, we incorporate the recent rise in real estate investment trusts (REITs) as a risk factor of the economic factors of silver futures, and the impact of the volatility index (VIX) and news events as risk factors of political factors to capture the impact of market news on rewards. This study uses text mining to capture news events on the Internet and the technique of word segmentation to convert text into a Boolean matrix to conform to normalized criteria and convert unstructured data into computer-analyzable structured data. This study also uses term frequency (TF) and inverse document frequency (IDF) algorithms to calculate the most important keywords on the market and incorporate them into the research model after a sentimental assessment. As measured using the model, the empirical results show that the silver futures ETF market is indeed affected by market news. Overall, the results of this study can be used as a reference for investors investing in the silver market. 


\subsection{Literature Review}

\subsubsection{Silver Futures ETFs}

From the 21st century, industrial demand for silver has increased substantially, making the metal scarcer and more precious. Accordingly, silver is expected to have a higher investment value and become a monetary metal with broad industrial use. The main sources of silver are the three aspects of new mining, silver scrap recycling, and government selling, and are mainly based on U.S. dollars. Consequently, economic and political factors, such as the economic cycle and an increase in the dollar, inflation, and other precious metal prices, can provide price shocks to silver. However, compared with gold spot trading, which is exempted from taxes, buying and selling silver are taxable transactions. This situation allows investors to put hedge funds into silver-derived goods that are exempt from taxes, resulting in the price discovery of silver futures.

In contrast, the silver spot price has greater volatility, and investors prefer to use the same amount of different silver futures to earn the bid-ask spread in silver price fluctuations or use the hedging function of silver futures to reduce investment risks. In addition, Ivanov (2013) pointed out that gold, silver, and crude oil ETFs have a strong correlation with their underlying assets. Moreover, through research, the leading function of the price discovery of gold and silver has been transferred from the futures market to the ETFs market. This transfer further strengthens the importance of the ETFs market, which should not be neglected. However, the leading function of the price discovery of crude oil is still in the futures and underlying assets markets rather than the ETFs. Hence, in the research model, this study does not include crude oil. In conclusion, to provide investors with more efficient risk management, this study analyzes the risks in the silver futures ETFs market to give investors more accurate judgment on trends in the silver market.

\subsubsection{Multi-Factor Capital Asset Pricing Model}

According to Sharpe's (1964) CAPM, the relationship between expected systemic risk and expected returns is simplified, and the model points out that receiving higher rewards is associated with higher risks. In addition, in 1993, Fama and French used the Fama-French three-factor model (FF3) to study the factors that determine the difference in returns among different stocks in the U.S. stock market. They found that the beta of the stock market could not explain the difference between different stock returns. However, they but pointed out that the market values of listed companies, which is different from the market value ratio, book value ratio, and company size, can explain differences in stock returns. Thus, explaining excess returns is related to the compensation for the beta in the CAPM that does not reflect systemic risk. Consequently, this study uses the CAPM as the basis and adds political and economic factors that affect silver futures ETFs as risk factors to ensure that the model can more accurately determine the risks and rewards of silver. 


\subsubsection{MSCI All Country World Index}

McCown and Zimmerman (2007) used MSCI as a market reward in the CAPM, confirming that both gold and silver were negatively correlated with the U.S. stock market during the study period. Both of the betas showed a strong negative correlation in the long term and the importance of precious metals for combating inflation and hedging. However, to more accurately measure the systemic risk of silver, this study incorporates the MSCI All Country World Index into the empirical research model as a systemic risk factor. The MSCI All Country World Index differs from the MSCI World Index in that the constituents of the MSCI World Index measure only developed countries, whereas constituents of the MSCI All Country World Index include not only developed countries at approximately $8 \%$ but also developing and emerging countries.

\subsubsection{Volatility Index}

The VIX, introduced in 1993 by the Chicago board options exchange, is a panic index used to measure the implied volatility of the S\&P 500 index and reflects the market's expectations of volatility and investor sentiment over the upcoming 30 days. In a study on the implied volatility and a future portfolio returns of Banerjee et al. (2007) explored the relationship between future returns and current implied volatility levels and innovations, and pointed out that the correlated variables of the VIX have strong prediction ability. Consequently, when the international political and economic situations are in a state of turmoil, investors tend to make their investments by the conservative way and invest their funds in financial instruments that are more transparent and easier to anticipate or manipulate. Thus, silver futures with hedging characteristics become a better choice for investors.

\subsubsection{Real Estate Investment Trusts}

REITs are an asset securitization concept that originated in the United States. Through the issuance of beneficiary certificates, real estate such as commercial buildings and shopping centers are divided into small units and sold to investors. The investment forms are similar to mutual funds. Funds raised by the operators can be invested in real estate, and investors can collect rental income from the real estate. The most attractive feature of REITs is that most of the rental income is allocated to investors. This type of investment method also represents a commodity-type hedging investment with silver futures. The investment income is relatively stable and can be divided into equity type, mortgage type, and hybrid type according to the investment targets. According to Park et al. (1990), who used Fama and Schwert (1977) to test the correlation between REITs and inflation rates, REITs had a negative correlation with the inflation rate during the sample period and can be regarded as a hedging tool for inflation. To summarize, McCown and Zimmerman (2007) used MSCI for market rewards in CAPM and concluded that silver and REITs are negatively correlated with the inflation rate. Therefore, this study intends to assume a positive correlation between silver futures ETFs and REITs. 
The rest of this study is organized as follows. The next section provides the model setting. Section 3 performs the empirical results. The final section presents the conclusions of this study.

\section{Model Framework}

The systemic risk between silver futures ETFs and the market can be proven using the capital asset pricing model (CAPM). To discover the multiple factors that influence silver futures ETFs, we extend the classical model and fit it with VIX, REITs, and market information.

$$
\begin{aligned}
E\left(R_{S L V}\right)-R_{f}= & \alpha+\beta_{S L V}\left(R_{M S C I}-R_{f}\right)+\varepsilon, \\
E\left(R_{S L V}\right)-R_{f}= & \alpha+\beta_{S L V}\left(R_{M S C I}-R_{f}\right)+\beta_{V I X} V I X+\varepsilon \\
E\left(R_{S L V}\right)-R_{f}= & \alpha+\beta_{S L V}\left(R_{M S C I}-R_{f}\right)+\beta_{V I X} V I X+\beta_{R E I T S} R E I T s+\varepsilon, \\
E\left(R_{S L V}\right)-R_{f}= & \alpha+\beta_{S L V}\left(R_{M S C I}-R_{f}\right)+\beta_{V I X} V I X+\beta_{R E I T S} \text { REITs } \\
& +\beta_{\text {KEYWORD }} \text { KEYWORD }+\varepsilon, \text { KEYWORD } \in\{\text { ten keywords }\} .
\end{aligned}
$$

Our analysis occurs in four phases. In the first phase, we research the systematic risk, where $E\left(R_{S L V}\right)$ is the expected rate of return for iShares Silver (SLV) and $R_{M S C I}$ represents the benchmark return (using the MSCI All Country World Index, MSCIACWI). The notation $R_{f}$ is the risk-free interest rate (using the yield rate on the U.S. one-year bond). We measure the excess return by computing the difference between the benchmark return and the risk-free interest rate. $\beta_{S L V}$ is the beta of systematic risk. The term $\alpha$ is the intercept. Notation $\varepsilon$ is the residual discrepancy that obeys the standard normal distribution. In the second phase, we incorporate the volatility index (using the logarithmic return of the VIX), and $\beta_{V I X}$ is the beta of the VIX. In the third phase, we fit into the logarithmic return of REITs (using FTSE 350 - REITs). Notation $\beta_{\text {REITs }}$ is the beta of the REITs. This study adopts daily datum for five years, from May 22, 2014, to May 22, 2019. The previous mentioned data are from Yahoo Finance. In particular, in the last phase, we incorporate market information into the model. This study adopts text mining in the analysis. We capture market information from Fortune 500 Daily \& Breaking Business News and extract the news from articles (unstructured data) to a frequency tabular format (structured data). After processing the aforementioned phases, the market information can be decoded via computer. Table 1 demonstrates the frequency data in tabular format. 
Table 1: Frequency tabular

\begin{tabular}{|c|c|c|c|c|}
\hline Frequency & Term $_{\mathbf{1}}$ & Term $_{\mathbf{2}}$ & Term $_{\mathbf{p}-\mathbf{1}}$ & Term $_{\mathbf{p}}$ \\
\hline Document1 & 3 & 4 & 0 & 1 \\
\hline Document2 & 1 & 0 & 4 & 3 \\
\hline Document $_{\mathbf{3}}$ & 2 & 1 & 0 & 0 \\
\hline Document $_{\mathbf{p}-\mathbf{1}}$ & 0 & 1 & 1 & 0 \\
\hline Document $_{\mathbf{p}}$ & 0 & 2 & 3 & 0 \\
\hline
\end{tabular}

\subsection{Term Frequency (TF):}

$T F_{i x}=\frac{n_{i x}}{\sum_{j=1}^{j=k} n_{j x}}, 1 \leq j \leq k$.

$n_{j x}$ : Among document $x$, the frequency of the specific term $j$.

$n_{i x}$ : Among document $x$, the frequency of the specific term $i$.

$k$ : Among document $x$, there are $k$ terms.

$T F_{i x}$ : Among document $x$, the term frequency (TF) of the specific term $i$.

This algorithm can provide the frequency of a term in the document.

A larger TF value indicates that a specific term has a higher frequency in the document and that the term implies a more important implication.

\subsection{Inverse Document Frequency (IDF):}

$I D F_{i x}=\log \frac{N}{d f_{i x}}$.

$\mathrm{N}$ : Total number of documents.

$d f_{i x}$ : Total number of documents that include the term $i$.

$I D F_{i x}$ : Among document $x$, the inverse document frequency of the specific term $i$.

Calculate how often the term appears in each document.

This algorithm can measure the uniqueness of the term among all documents.

A smaller IDF value indicates that the more frequently the term appears in documents, implying that the term has less distinctiveness.

\subsection{TF-IDF}

$T F-I D F_{i x}=\frac{n_{i x}}{\sum_{j=1}^{j=k} n_{j x}} \times \log \frac{N}{d f_{i x}}$.

The importance and uniqueness of a specific term can be measured at the same time. This equation is generally used to measure the criticality of the term in many documents. 
Table 2: Boolean valued expression matrix

\begin{tabular}{|c|c|c|c|c|c|}
\hline Frequency & Term $_{\mathbf{1}}$ & Term $_{\mathbf{2}}$ & Term $_{\mathbf{3}}$ & Term $_{\mathbf{4}}$ & Term $_{\mathbf{5}}$ \\
\hline Document $_{\mathbf{1}}$ & 1 & 1 & 0 & 0 & 1 \\
\hline Document $_{\mathbf{2}}$ & 1 & 0 & 1 & 1 & 1 \\
\hline Document $_{\mathbf{3}}$ & 1 & 1 & 0 & 0 & 0 \\
\hline Document $_{\mathbf{p}-\mathbf{1}}$ & 0 & 1 & 1 & 1 & 0 \\
\hline Document $_{\mathbf{p}}$ & 1 & 0 & 1 & 1 & 0 \\
\hline
\end{tabular}

\section{Empirical Analysis}

As shown in Table 3, the estimated results of the original model show that a significantly positive correlation exists between the excess return of the MSCIACWI and of silver futures ETFs, indicating that the model can capture the systematic risk in the silver futures ETFs market. The VIX return has a significant positive influence on silver futures ETFs. This result can be interpreted as follows. When the VIX increases, investors expect that the volatility in the market will be more intense. Moreover, this result reflects the precarious mentation, indicating that investors will invest more in a hedge, causing an increase in the demand for silver futures and silver futures returns moving similarly to the VIX. Relatively, when the VIX's returns decrease, investors expect the market volatility also to decrease. Investors' sentiments are more stable, and the demand for hedges decreases, causing the demand for silver futures to diminish and silver futures returns to decline with the VIX. Therefore, the VIX significantly reflects the price movement of silver futures ETFs. Investors can hedge more accurately using silver futures ETFs and reduce a portfolio's risk. Nevertheless, REIT rewards are contrary to the aforementioned literature review in terms of assuming a positive correlation between silver futures ETFs and REITs. Conversely, a significantly negative correlation exists between REITs and silver futures ETFs. We can infer that hedging investors have limited capital. If they increase their capital investments in REITs, silver futures demand will decrease. Conversely, if investors decrease their capital investments in REITs, silver futures demand will increase. As REIT returns decrease, the expected return of silver futures ETFs will increase. Therefore, the price variation of REITs can be, in reverse, the determinate foundation of silver futures. Investors can hedge more accurately using silver futures ETFs and improve investing efficiency. 
Table 3: Empirical results of regression models on silver futures ETF $(2014 / 5 / 22-2019 / 5 / 22)$

\begin{tabular}{|c|c|c|c|}
\hline \multirow{\beta}{\beta}{ coefficient } & Original Model & Extended Model & Extended Model \\
\hline \multirow{2}{*}{$\boldsymbol{\beta}_{\text {SLV }}$} & 1.0462 & 1.0474 & 1.0450 \\
\cline { 2 - 4 } & $(0.000)$ & $(0.000)$ & $(0.000)$ \\
\hline \multirow{2}{*}{$\boldsymbol{\beta}_{\text {VIX }}$} & & 0.0516 & 0.0432 \\
\cline { 2 - 4 } & & $(0.000)$ & $(0.000)$ \\
\hline \multirow{2}{*}{$\boldsymbol{\beta}_{\text {REITs }}$} & & & -0.1921 \\
\hline $\boldsymbol{R}$-squared & 0.917 & 0.925 & $0.000)$ \\
\hline Adj. $\boldsymbol{R}$-squared & 0.917 & 0.925 & 0.927 \\
\hline
\end{tabular}

Note: Values in parentheses are p-values.

Table 4 provides the statistical results of TF-IDF and the top ten keywords. Tables 5 to 7 provide the estimated results after fitting into keywords.

Table 4: TF-IDF statistical results

\begin{tabular}{|c|c|}
\hline Keyword & TF-IDF \\
\hline shares & 0.02274334235733471 \\
\hline fund & 0.019775236028875497 \\
\hline interest & 0.01750818548965358 \\
\hline earnings & 0.01730788383558578 \\
\hline government & 0.017134896043436317 \\
\hline Fed & 0.015827739149321434 \\
\hline funds & 0.01572393448906667 \\
\hline New York & 0.013692328995509173 \\
\hline global & 0.013194910276024097 \\
\hline Goldman & 0.012832216265339733 \\
\hline
\end{tabular}


As shown in Table 5, a significantly positive correlation exists between silver futures ETFs and each of the keywords "Fed," "funds," and "global." This correlation represents that information released by the Fed or worldwide information may cause investors to invest in hedge funds and adopt more conservative strategies, and they react very quickly. Most respond quickly.

Table 5: Zero-day time lag statistical results

\begin{tabular}{|c|c|c|c|c|c|}
\hline $\begin{array}{c}\boldsymbol{\beta} \\
\text { coefficient }\end{array}$ & $\boldsymbol{\beta}_{\text {SLV }}$ & $\boldsymbol{\beta}_{\text {VIX }}$ & $\boldsymbol{\beta}_{\text {REITS }}$ & $\boldsymbol{\beta}_{\text {KEYWORD }}$ & $\begin{array}{c}\text { Adj. } \\
\boldsymbol{R} \text {-squared }\end{array}$ \\
\hline \multirow{2}{*}{ Fed } & 1.0455 & 0.0439 & -0.1897 & 0.0021 & 0.927 \\
& $(0.000)$ & $(0.000)$ & $(0.000)$ & $(0.005)$ & \\
\hline \multirow{2}{*}{ funds } & 1.0446 & 0.0432 & -0.1957 & 0.0018 & 0.927 \\
& $(0.000)$ & $(0.000)$ & $(0.000)$ & $(0.021)$ & \\
\hline \multirow{2}{*}{ global } & 1.0447 & 0.0437 & -0.1912 & 0.0018 & 0.927 \\
& $(0.000)$ & $(0.000)$ & $(0.000)$ & $(0.030)$ & \\
\hline
\end{tabular}

Note: Values in parentheses are $p$-values.

Table 6 shows that a significant positive correlation exists between silver futures ETFs and the keyword "shares." As changes in market shares or equity are incorporated, they may cause a more unstable market ambiance. Investors will invest more in hedge funds, and they respond in a short period.

Table 6: One-day time lag statistical results

\begin{tabular}{|c|c|c|c|c|c|}
\hline $\begin{array}{c}\boldsymbol{\beta} \\
\text { coefficient }\end{array}$ & $\boldsymbol{\beta}_{\text {SLV }}$ & $\boldsymbol{\beta}_{\text {VIX }}$ & $\boldsymbol{\beta}_{\text {REITS }}$ & $\boldsymbol{\beta}_{\text {KEYWORD }}$ & $\begin{array}{c}\text { Adj. } \\
\text { R-squared }\end{array}$ \\
\hline \multirow{2}{*}{ Shares } & 1.0440 & 0.0436 & -0.1960 & 0.0020 & 0.927 \\
& $(0.000)$ & $(0.000)$ & $(0.000)$ & $(0.039)$ & \\
\hline
\end{tabular}

Note: Values in parentheses are $p$-values. 
As shown in Table 7, a significant positive correlation exists between silver futures ETFs and the keyword "New York." Because New York City is a financial center, any market information or alteration that occurs in this city may increase investors' motivation to hedge.

Table 7: Two-day time lag statistical results

\begin{tabular}{|c|c|c|c|c|c|}
\hline $\begin{array}{c}\boldsymbol{\beta} \\
\text { coefficient }\end{array}$ & $\boldsymbol{\beta}_{\text {SLV }}$ & $\boldsymbol{\beta}_{\text {VIX }}$ & $\boldsymbol{\beta}_{\text {REITs }}$ & $\boldsymbol{\beta}_{\text {KEYWORD }}$ & $\begin{array}{c}\text { Adj. } \\
\text { R-squared }\end{array}$ \\
\hline \multirow{2}{*}{ New York } & 1.0454 & 0.0437 & -0.1903 & 0.0017 & 0.927 \\
& $(0.000)$ & $(0.000)$ & $(0.000)$ & $(0.044)$ & \\
\hline
\end{tabular}

Note: Values in parentheses are $p$-values.

As shown in Tables 8 and 9, a significant negative correlation exists between silver futures ETFs and each of the keywords "earnings" and "government." The keyword "interest" is non-significant at the 5\% significance level; nevertheless, when we put together "interest," "earnings," and "government," the keyword "interest" then has a significant positive correlation to silver futures ETFs. When release information on earnings is incorporated, investors turn to more active strategies and decreasing hedge demand. When the government adopts financial or international policies that provide an advantageous investment environment, investors decrease their hedging demands. If corporations have appropriate performance, the market is prosperous, and governments provide an advantageous investment environment, the interest rate may be adjusted to provide a lower opportunity cost of capital, and people become willing to invest in hedge funds.

Table 8: Three-day time lag statistical results.

\begin{tabular}{|c|c|c|c|c|c|}
\hline $\begin{array}{c}\boldsymbol{\beta} \\
\text { coefficient }\end{array}$ & $\boldsymbol{\beta}_{\text {SLV }}$ & $\boldsymbol{\beta}_{\text {VIX }}$ & $\boldsymbol{\beta}_{\text {REITs }}$ & $\boldsymbol{\beta}_{\text {KEYWORD }}$ & $\begin{array}{c}\text { Adj. } \\
\boldsymbol{R} \text {-squared }\end{array}$ \\
\hline \multirow{2}{*}{ interest } & 1.0447 & 0.0436 & -0.1925 & 0.0013 & 0.927 \\
& $(0.000)$ & $(0.000)$ & $(0.000)$ & $(0.157)$ & \\
\hline \multirow{2}{*}{ earnings } & 1.0451 & 0.0432 & -0.1947 & -0.0021 & 0.927 \\
& $(0.000)$ & $(0.000)$ & $(0.000)$ & $(0.008)$ & \\
\hline \multirow{2}{*}{ government } & 1.0451 & 0.0430 & -0.1938 & -0.0025 & 0.927 \\
& $(0.000)$ & $(0.000)$ & $(0.000)$ & $(0.003)$ & \\
\hline
\end{tabular}

Note: Values in parentheses are $p$-values. 
Table 9: Three-day time lag statistical results (keywords combination).

\begin{tabular}{|c|c|c|c|c|c|c|c|}
\hline & $\boldsymbol{\beta}_{\text {SLV }}$ & $\boldsymbol{\beta}_{\text {VIX }}$ & $\boldsymbol{\beta}_{\text {REITs }}$ & $\boldsymbol{\beta}_{\text {interest }}$ & $\boldsymbol{\beta}_{\text {earnings }}$ & $\boldsymbol{\beta}_{\text {government }}$ & $\begin{array}{c}\text { Adj. } \\
\text { R-squared }\end{array}$ \\
\hline $\begin{array}{c}\boldsymbol{\beta} \\
\text { coefficient }\end{array}$ & 1.0441 & 0.0430 & -0.1967 & 0.0026 & -0.0022 & -0.0027 & 0.928 \\
& $(0.000)$ & $(0.000)$ & $(0.000)$ & $(0.005)$ & $(0.009)$ & $(0.002)$ & \\
\hline
\end{tabular}

Note: Values in parentheses are $p$-values.

Tables 10 and 11 show that a significant negative correlation exists between silver futures ETFs and the keywords "earnings," and "fund" that is non-significant at the $5 \%$ significance level. However, when we combine "fund" and "earnings" in a model, "fund" becomes significant. Corporations' earnings can set up a bridge between silver futures ETFs and other funds.

Table 10: Five-day time lag statistical results

\begin{tabular}{|c|c|c|c|c|c|}
\hline $\begin{array}{c}\boldsymbol{\beta} \\
\text { coefficient }\end{array}$ & $\boldsymbol{\beta}_{\text {SLV }}$ & $\boldsymbol{\beta}_{\text {VIX }}$ & $\boldsymbol{\beta}_{\text {REITs }}$ & $\boldsymbol{\beta}_{\text {KEYWORD }}$ & $\begin{array}{c}\text { Adj. } \\
\boldsymbol{R} \text {-squared }\end{array}$ \\
\hline \multirow{2}{*}{ fund } & 1.0459 & 0.0437 & -0.1904 & 0.0014 & 0.925 \\
& $(0.000)$ & $(0.000)$ & $(0.000)$ & $(0.094)$ & \\
\hline \multirow{2}{*}{ earnings } & 1.0455 & 0.0433 & -0.1894 & -0.0020 & 0.926 \\
& $(0.000)$ & $(0.000)$ & $(0.000)$ & $(0.013)$ & \\
\hline
\end{tabular}

Note: Values in parentheses are $p$-value.

Table 11: Five-day time lag statistical results (keywords combination)

\begin{tabular}{|c|c|c|c|c|c|c|}
\hline & $\boldsymbol{\beta}_{\text {SLV }}$ & $\boldsymbol{\beta}_{\text {VIX }}$ & $\boldsymbol{\beta}_{\text {REITs }}$ & $\boldsymbol{\beta}_{\text {fund }}$ & $\boldsymbol{\beta}_{\text {earnings }}$ & $\begin{array}{c}\text { Adj. } \\
\boldsymbol{R} \text {-squared }\end{array}$ \\
\hline $\begin{array}{c}\boldsymbol{\beta} \\
\text { coefficient }\end{array}$ & 1.0456 & 0.0435 & -0.1875 & 0.0017 & -0.0022 & 0.926 \\
& $(0.000)$ & $(0.000)$ & $(0.000)$ & $(0.041)$ & $(0.006)$ & \\
\hline
\end{tabular}

Note: Values in parentheses are $p$-values. 
As shown in Table 12, a significant positive correlation exists between silver futures ETFs and the keyword "Goldman." The Goldman Sachs Group, Inc. is an investment bank that provides investment management, asset management, and other related services. Market information liberated by this organization that has credibility can influence the fund market.

Table 12: Seven-day time lag statistical results.

\begin{tabular}{|c|c|c|c|c|c|}
\hline $\begin{array}{c}\boldsymbol{\beta} \\
\text { coefficient }\end{array}$ & $\boldsymbol{\beta}_{\text {SLV }}$ & $\boldsymbol{\beta}_{\text {VIX }}$ & $\boldsymbol{\beta}_{\text {REITS }}$ & $\boldsymbol{\beta}_{\text {KEYWORD }}$ & $\begin{array}{c}\text { Adj. } \\
\text { R-squared }\end{array}$ \\
\hline Goldman & 1.0450 & 0.0434 & -0.1905 & 0.0019 & 0.926 \\
& $(0.000)$ & $(0.000)$ & $(0.000)$ & $(0.011)$ & \\
\hline
\end{tabular}

Note: Values in parentheses are $p$-values.

\section{Conclusion}

This study applies the multi-factor CAPM to analyze the impact of market excess returns on silver futures ETFs. This study also considers REITs, which influence the economic factors of silver futures as the risk factors, and the VIX, as the risk factors under political consideration, to further analyze the impact on the precious metals ETFs market. In addition, we consider the influence of the news and identify keywords using text mining techniques, and include them in the model to examine their impact. The empirical results show that the research model captures the influence of excess returns of the MSCI All Country World Index on silver futures ETFs. The returns and volatility are synchronized with the benchmark. Significant systematic risk exists, and the VIX is positive for silver futures ETFs, whereas REITs have a negative impact. The results reflect the influence of investor sentiment and demand changes on silver futures ETFs. When sentiments tend to be unstable, the demand for hedging assets increases and silver futures ETF returns increase. Moreover, an increase in the demand for other hedging assets, such as REITs, may affect the demand for the silver futures ETFs, causing their returns to decline. Finally, the results of the analysis of the relevant market news on silver show that keywords such as "shares," "fund," "interest," "earnings," "government," "Fed," "funds," "New York," "global," and "Goldman" are significantly influential on silver futures ETFs. Investors respond quickly to the information released by the Fed and worldwide information and are inclined to adopting a conservative strategy and investing in hedge funds as silver futures ETFs. As corporations' market share or equity changes, investors also invest more in hedge funds. Market information from New York City may increase the motivation of investors to hedge. When a corporation's earnings cause investors to participate in the stock market and decrease their demands on hedge funds. Governments may provide an advantageous investment environment, which incentivizes investors toward active strategies and decreasing their demand for hedge funds. The performance of corporations and the 
government can affect the influence of interest rates on silver futures ETFs. The keyword "earnings" can also set up a bridge between silver futures ETFs and other funds. Market information liberated by the Goldman Sachs Group has the credibility needed to influence the hedge funds market. In addition to presenting academic contributions, this study also provides investment references in the precious metal futures ETFs market and key points of concern for related keywords and issues.

\section{ACKNOWLEDGEMENTS.}

Yu-Min Lian is grateful to the Ministry of Science and Technology (MOST) for support through Project No.: MOST109-2410-H-030-019-MY2.

\section{References}

[1] Banerjee, P. S., Doran, J. S., Peterson, D. R. (2007). Implied volatility and future portfolio returns. Journal of Banking and Finance, Vol. 31, pp. 31833199.

[2] Fama, E. F., French, K. R. (1993). Common risk factors in the returns on stocks and bonds. Journal of Financial Economics, Vol. 33, pp. 3-56.

[3] Fama, E. F., Schwert, G. W. (1977). Asset returns and Inflation. Journal of Financial Economics, Vol. 5, pp. 115-146.

[4] Ivanov, S. I. (2013). The influence of ETFs on the price discovery of gold, silver and oil. Journal of Economics and Finance, Vol. 37, pp. 453-462.

[5] McCown, J. R., Zimmerman, J. R. (2007). Analysis of the investment potential and inflation-hedging ability of precious metals. Available online by https://papers.ssrn.com/sol3/papers.cfm?abstract_id=1002966

[6] Park, J. Y., Mullineaux, D. J., Chew, I.-K. (1990). Are REITs inflation hedges? Journal of Real Estate Finance and Economics, Vol. 3, pp. 91-103.

[7] Sharpe, W. (1964). Capital asset prices: A theory of market equilibrium under conditions of risk. Journal of Finance, Vol.19, pp. 1425-442. 